\title{
Multicentre consensus recommendations for skin care in inherited epidermolysis bullosa
}

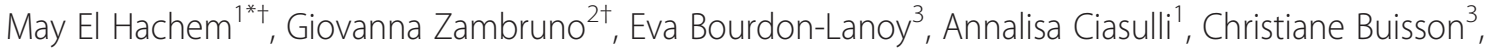 \\ Smail Hadj-Rabia ${ }^{3,4}$, Andrea Diociaiuti ${ }^{1}$, Carolina F Gouveia ${ }^{5}$, Angela Hernández-Martín ${ }^{6}$, Raul de Lucas Laguna ${ }^{7}$, \\ Mateja Dolenc-Voljč ${ }^{8}$, Gianluca Tadini ${ }^{9}$, Guglielmo Salvatori ${ }^{10}$, Cristiana De Ranieri ${ }^{11}$, \\ Stephanie Leclerc-Mercier ${ }^{3}$ and Christine Bodemer ${ }^{3,4^{*}}$
}

\begin{abstract}
Background: Inherited epidermolysis bullosa (EB) comprises a highly heterogeneous group of rare diseases characterized by fragility and blistering of skin and mucous membranes. Clinical features combined with immunofluorescence antigen mapping and/or electron microscopy examination of a skin biopsy allow to define the EB type and subtype. Molecular diagnosis is nowadays feasible in all EB subtypes and required for prenatal diagnosis. The extent of skin and mucosal lesions varies greatly depending on EB subtype and patient age. In the more severe EB subtypes lifelong generalized blistering, chronic ulcerations and scarring sequelae lead to multiorgan involvement, major morbidity and life-threatening complications. In the absence of a cure, patient management remains based on preventive measures, together with symptomatic treatment of cutaneous and extracutaneous manifestations and complications. The rarity and complexity of EB challenge its appropriate care. Thus, the aim of the present study has been to generate multicentre, multidisciplinary recommendations on global skin care addressed to physicians, nurses and other health professionals dealing with $\mathrm{EB}$, both in centres of expertise and primary care setting.
\end{abstract}

Methods: Almost no controlled trials for EB treatment have been performed to date. For this reason, recommendations were prepared by a multidisciplinary team of experts from different European EB centres based on available literature and expert opinion. They have been subsequently revised by a panel of external experts, using an online-modified Delphi method to generate consensus.

Results: Recommendations are reported according to the age of the patients. The major topics treated comprise the multidisciplinary approach to EB patients, global skin care including wound care, management of itching and pain, and early diagnosis of squamous cell carcinoma. Aspects of therapeutic patient education, care of disease burden and continuity of care are also developed.

Conclusion: The recommendations are expected to be useful for daily global care of EB patients, in particular in the community setting. An optimal management of patients is also a prerequisite to allow them to benefit from the specific molecular and cell-based treatments currently under development.

Keywords: Inherited epidermolysis bullosa, Multidisciplinary management recommendations, Skin care, Wound care, Itch, Pain, Therapeutic education, Disease burden, Quality of life, Continuity of care

\footnotetext{
*Correspondence: may.elhachem@opbg.net; christine.bodemer@nck.aphp.fr

${ }^{\dagger}$ Equal contributors

'Dermatology Unit, Bambino Gesù Children's Hospital, IRCCS, Piazza S.

Onofrio, 4, 00165 Rome, Italy

${ }^{3}$ Department of Dermatology, Necker-Enfants Malades Hospital, National reference centre for Genodermatoses (MAGEC), 149 rue de Sèvres, 75015

Paris, France

Full list of author information is available at the end of the article
}

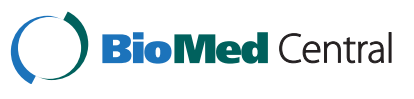

(c) 2014 El Hachem et al.; licensee BioMed Central Ltd. This is an Open Access article distributed under the terms of the Creative Commons Attribution License (http://creativecommons.org/licenses/by/2.0), which permits unrestricted use, distribution, and reproduction in any medium, provided the original work is properly credited. The Creative Commons Public Domain Dedication waiver (http://creativecommons.org/publicdomain/zero/1.0/) applies to the data made available in this article, unless otherwise stated. 


\section{Background}

Inherited epidermolysis bullosa (EB) refers to a clinically and genetically heterogeneous group of rare disorders characterized by fragility of the skin and mucous membranes. Based on the site of blister formation, four major types of EB are currently distinguished: EB simplex (EBS), junctional EB (JEB), dystrophic EB (DEB), and Kindler syndrome (KS); each one is then subdivided into several subtypes based on the mode of transmission and a combination of phenotypic, immunofluorescence, ultrastructural and molecular findings [1]. Once the cleavage level and protein expression pattern has been determined, molecular testing is the most accurate diagnostic procedure for EB subtype definition. Furthermore, it is required for DNA-based prenatal diagnosis. The extent and severity of skin and mucous membrane lesions and multiorgan involvement vary markedly in the different EB types and subtypes and in relation to age [1-5]. In several EB subtypes, the cutaneous and extracutaneous manifestations and complications lead to a significant morbidity and even to premature death. The rarity of EB and the phenotypic variability challenge the appropriate care of these patients.

Despite the preclinical development of different molecular and cell-based treatment strategies, no cure is still available for EB [6]. In the absence of a specific therapy, patient management is currently centered on preventive and skin care measures, and early recognition and symptomatic treatment of complications. As almost no controlled trials for EB treatment have been performed to date [7], measures for EB management mainly rely on the experience of physicians, nurses and other involved healthcare professionals. The development of consensus recommendations based on literature data and shared expertise among experts from different countries represents an important step towards improved standard of care and quality of life for affected patients and their caregivers. Consensus recommendations based on best evidence available have been recently generated by an international panel of EB experts [8]. They comprise 17 items centered on wound care and related general health and patient issues. In addition, comprehensive best practice guidelines addressing all aspects of oral health care in EB have been published [9]. Finally, guidelines for wound and skin care in the major EB types have been generated by clinical experts and made available on the Debra International website [10]. These documents provide an invaluable support for the treatment of specific and major manifestations of EB disease. However, they do not address several equally important disease-related aspects such as the multidisciplinary management organization, therapeutic patient education, care of disease burden and continuity of care. We have therefore developed a list of consensus recommendations on current best practices for global skin care in EB. They are conceived to provide a practical support for day-today management of patients both in a hospital setting and in community care. Our aim has been to consider all aspects of patient life affected by the skin disease and also the family burden. The recommendations are addressed to all healthcare professionals dealing with EB both in centres of expertise and in community care: physicians (dermatologists, neonatologists, pediatricians, internists, pain relief doctors, anesthetists, surgeons, general practitioners), nurses, dieticians, psychologists, physical and occupational therapists, and social workers. They are expected to be useful also for patients and their caregivers.

\section{Methods}

A multidisciplinary group of experts in EB diagnosis and care from different European countries (France, Italy and Portugal) met in Paris in October 2011 at the occasion of the closing meeting of the EU-supported project "Together Against Genodermatoses". It was decided to generate a list of consensus recommendations on current best practices for global skin care in patients affected with all types of EB. A list of topics was identified and subgroups of experts revised the pertinent literature (English, French and Italian) since January 2000. Older articles deemed relevant by the experts were also considered. Literature search included all published recommendations and guidelines on EB care. A provisional list of recommendations for each topic was then prepared. The resulting global document was revised by additional experts from Spain and Slovenia and then circulated among a second group of experts using an onlinemodified Delphi method to generate consensus. The final document is reported below.

\section{Multidisciplinary management of EB patients}

The fragility of the skin and mucous membranes in EB patients results in the involvement of many organs and systems [1-5,11-18] (Tables 1 and 2). In addition, disease manifestations vary upon the age of the patients and the EB type and subtype.

\section{General principles}

- Treatment of EB patients should be performed in centres of expertise adhering to the recommendations for quality criteria issued by the European Union Committee of Experts on Rare Diseases (EUCERD) [19].

- Centres of expertise should also guarantee the continuity of care between pediatric age and adulthood [20].

- A coordinated multidisciplinary approach must be adopted (Table 3).

- The coordinator of the team should be a dermatologist in order to ensure both an integrated 
Table 1 Major epidermolysis bullosa complications affecting the skin, eye and ENT area

\begin{tabular}{|c|c|c|}
\hline Tissue/organ/system & Major complications & EB type/subtype* \\
\hline \multirow[t]{13}{*}{ Skin } & Fluid loss & Lethal acantholytic EB, JEB-H, EBS-PA, JEB-PA \\
\hline & Chronic/infected wounds & $\begin{array}{l}\text { RDEB-SG, RDEB-I, RDEB-O, JEB-H, JEB-nH, EBS-AR, DEB-Pr, } \\
\text { DDEB-G, EBS-DM }\end{array}$ \\
\hline & Exuberant granulation tissue & LOC, JEB-H, JEB-nH \\
\hline & Atrophic scars, post-inflammatory pigmentary changes & DEB, JEB, EBS \\
\hline & Poikiloderma/diffuse skin atrophy & KS \\
\hline & Excessive/hypertrophic scarring & RDEB-SG, RDEB-I, DEB-Pt, DEB-Pr, RDEB-O \\
\hline & Albopapuloid lesions & DEB \\
\hline & Milia & DEB, JEB, EBS, KS \\
\hline & Palmoplantar keratoderma & EBS, JEB-nH, KS \\
\hline & Aplasia cutis congenita & EBS-PA, JEB-PA, DEB, other JEB and EBS subtypes \\
\hline & EB nevi & JEB, DEB, EBS \\
\hline & Basal cell carcinomas & EBS-DM \\
\hline & Squamous cell carcinomas & RDEB-SG, RDEB-O, KS, JEB-nH, RDEB-I \\
\hline \multirow[t]{4}{*}{ Skin adnexa } & Onychodystrophy, nail shedding or loss & DEB, JEB, EBS-MD, EBS-DM, EBS-PD, EBS-AR, EBS-O, KS \\
\hline & Scarring alopecia & JEB-nH, RDEB-SG, JEB-H, JEB-PA, RDEB-O \\
\hline & Alopecia universalis & Lethal acantholytic EB \\
\hline & Hypotrichosis & EBS-PD \\
\hline \multirow[t]{4}{*}{ Oral cavity } & Microstomia, ankyloglossia, obliteration of the oral vestibules & RDEB-SG, RDEB-I, RDEB-O \\
\hline & Enamel hypoplasia & JEB, EBS-MD \\
\hline & Multiple caries and tooth decay & DEB, JEB \\
\hline & Periodontitis & KS \\
\hline \multirow[t]{6}{*}{ External eye } & Corneal erosions & RDEB-SG, JEB-H, RDEB-O, RDEB-I, JEB-nH, EBS-DM, KS \\
\hline & Blepharitis, corneal scarring and/or pannus formation & RDEB-SG, RDEB-I, JEB-H, RDEB-O, JEB-nH \\
\hline & Symblepharon & LOC, RDEB-SG, RDEB-I, JEB-H, JEB-nH \\
\hline & Ectropion/exposure keratitis & JEB-H, RDEB-SG, KS \\
\hline & Diminished vision/blindness & RDEB-SG \\
\hline & Conjunctival granulation tissue & LOC \\
\hline External ear & External auditory canal narrowing/conductive hearing loss & RDEB-I \\
\hline Nose & Nare narrowing (granulation tissue) & JEB-H, JEB-nH, LOC \\
\hline
\end{tabular}

*The epidermolysis bullosa (EB) types and subtypes which present a higher frequency of a given complication are listed first.

EBS, epidermolysis bullosa simplex; EBS-PA, EBS with pyloric atresia; EBS-DM, EBS, Dowling-Meara; EBS-MD, EBS with muscular dystrophy; EBS-AR, EBS, autosomal recessive; EBS-PD, plakophilin deficiency; EBS-O, EBS, generalized other; JEB, junctional epidermolysis bullosa; JEB-H, JEB, Herlitz; JEB-nH, JEB, non-Herlitz; JEB-PA, JEB with pyloric atresia; LOC, laryngo-onycho-cutaneous syndrome; DEB, dystrophic epidermolysis bullosa; DDEB, dominant DEB; DDEB-G, DDEB, generalized; RDEB-SG, recessive DEB, severe generalized; RDEB-O, recessive DEB, generalized other; RDEB-I, recessive DEB, inversa; DEB-Pr, DEB, pruriginosa; DEB-Pt, pretibial DEB; KS, Kindler syndrome.

management and continuity of care with the community healthcare system [21-30].

- The multidisciplinary management is centered on the patient; therefore, it is a tailored treatment for each patient.

- The multidisciplinary team should be specifically trained and regularly updated [19].

\section{Care of the EB newborn and infant}

Several procedures performed in newborns and infants can severely injury the EB fragile skin and require specific and adapted care measures [10,31,32]. In addition, the skin immaturity in pre-term newborns affected with $\mathrm{EB}$ and the ongoing functional skin adaptation to the extra-uterine environment in term babies demand particular caution in skin handling and care. Skin and mucosal lesions predispose to recurrent and potentially life-threatening infections and cause loss of fluids and electrolytes which can lead to dehydration and electrolyte imbalance. Although the extent and severity of skin and mucous membrane involvement is extremely variable, general and specific measures for skin care of the newborn and infant affected with EB can be recommended. 
Table 2 Other major extracutaneous complications of epidermolysis bullosa

\begin{tabular}{|c|c|c|}
\hline Tissue/organ/system & Major complications & EB type/subtype* \\
\hline \multirow[t]{7}{*}{ Gastrointestinal tract } & Pyloric atresia & JEB-PA, EBS-PA \\
\hline & Esophageal stenosis/strictures/web formation & RDEB-SG, RDEB-I, KS, RDEB-O \\
\hline & Chronic constipation/fecal impaction & RDEB-SG, RDEB-I, RDEB-O, DDEB, JEB-H, JEB-nH, EBS-DM, EBS-MD \\
\hline & Gastroesophageal reflux disease & RDEB, JEB-nH, EBS-DM, EBS-MD, JEB-PA, JEB-H, DDEB \\
\hline & Anal fissures/stenosis & RDEB-SG, RDEB-I, RBED-O, KS \\
\hline & Protein-loosing enteropathy & JEB-PA, EBS-PA, JEB-H, JEB-nH \\
\hline & Colitis/diarrhea & $\mathrm{KS}$, RDEB, JEB-PA \\
\hline \multirow[t]{4}{*}{ Genitourinary tract } & Urethral strictures, meatal stenosis & JEB-H, RDEB-SG, JEB-PA, JEB-nH, LOC, KS \\
\hline & $\begin{array}{l}\text { Genitourinary malformations, ureteral/ureterovesical } \\
\text { junction obstruction/stenosis, recurrent cystitis }\end{array}$ & JEB-PA, EBS-PA \\
\hline & Vulvar/vaginal scarring/strictures & RDEB-I, KS \\
\hline & Renal failure & RDEB-SG, JEB-PA, JEB-nH \\
\hline Upper respiratory tract & Tracheolaryngeal stenosis/acute respiratory failure & JEB-H, LOC, EBS-MD, lethal acantholytic EB, EBS-DM \\
\hline \multirow[t]{5}{*}{ Musculoskeletal system } & Osteopenia and osteoporosis & RDEB-SG, RDEB-O, JEB-nH \\
\hline & Limb flexion contractures & RDEB-SG \\
\hline & Digit contractures/pseudosyndactyly & RDEB-SG, RDEB-O, RDEB-I, KS \\
\hline & Mitten deformities & RDEB-SG \\
\hline & Muscular dystrophy & EBS-MD, EBS-PA \\
\hline Hematopoietic system & Multifactorial anemia & RDEB-SG, JEB-H, JEB-PA, EBS-PA, JEB-nH, EBS-AR, EBS-DM, RDEB-O \\
\hline Heart & Dilated cardiomyopathy & RDEB-SG, JEB-nH, EBS-MD \\
\hline Endocrine & Delayed puberty, amenorrhea & RDEB-SG, RDEB-O \\
\hline \multirow[t]{2}{*}{ Systemic complications } & Sepsis & JEB-H, JEB-nH, RDEB-SG, EBS-DM \\
\hline & Failure to thrive, growth retardation & $\begin{array}{l}\text { JEB-H, JEB-PA, EBS-PA, RDEB-SG, JEB-nH, RDEB-O, EBS-AR, } \\
\text { EBS-DM, RDEB-I }\end{array}$ \\
\hline
\end{tabular}

*The EB types and subtypes which present a higher frequency of a given complication are listed first.

EBS, epidermolysis bullosa simplex; EBS-PA, EBS with pyloric atresia; EBS-DM, EBS, Dowling-Meara; EBS-MD, EBS with muscular dystrophy; EBS-AR, EBS, autosomal recessive; EBS-PD, plakophilin deficiency; EBS-O, EBS, generalized other; JEB, junctional epidermolysis bullosa; JEB-H, JEB, Herlitz; JEB-nH, JEB, non-Herlitz; JEB-PA, JEB with pyloric atresia; LOC, laryngo-onycho-cutaneous syndrome; DEB, dystrophic epidermolysis bullosa; DDEB, dominant DEB; DDEB-G, DDEB, generalized; RDEB,recessive DEB; RDEB-SG, recessive DEB, severe generalized; RDEB-O, recessive DEB, generalized other; RDEB-I, recessive DEB, inversa; DEB-Pr, DEB, pruriginosa; DEB-Pt, pretibial DEB; KS, Kindler syndrome.

\section{General principles}

- The first multidisciplinary care should be provided independently from the diagnostic definition of the EB type and subtype.

- Diagnosis should be performed as soon as possible in order to implement the most appropriate treatment, communicate the diagnosis and specific information to the parents. Methods and criteria for diagnosis have been regularly updated by an International Consensus Conference [1].

- The communication of the diagnosis should involve the dermatologist and the neonatologist and should be addressed to both parents. The information should be delivered gradually and adapted to the family socio-cultural level.

- A psychologist should support the family (see paragraph "Care of disease burden").

- Caregiver education should start promptly (see paragraph "Therapeutic patient education").
- Members of the multidisciplinary team usually involved in EB care in infancy are neonatologist/ pediatrician, dermatologist, anesthetist, pathologist, medical geneticist, psychologist and specialized nurses.

\section{General measures}

- Blood sampling for complete blood count, electrolytes, C-reactive protein, urea, creatinine, total serum protein and albumin, iron, zinc, and, whenever required, blood cultures. Swabs for culture should be taken from infected wounds.

- In severely affected newborns, a venous access should be guaranteed through placement of an umbilical venous catheter. Whenever required, this will be followed by elective insertion of an indwelling central venous catheter (tunnelled external design such as Broviac catheters). 


\begin{tabular}{ll} 
Table $\mathbf{3}$ Specialists involved in multidisciplinary \\
epidermolysis bullosa care & \\
\hline Physicians & Other professionals \\
\hline Dermatologist & Specialist nurse \\
Neonatologist/pediatrician/internist & Dietitian \\
Pathologist & Psychologist \\
Medical geneticist & Dental hygienist \\
Otolaryngologist & Physical therapist \\
Ophthalmologist & Occupational therapist \\
(Pediatric) surgeon & Speech therapist \\
Orthopedic surgeon & Social worker \\
Plastic surgeon & \\
(Pediatric) gastroenterologist & \\
Dentist & \\
(Pediatric) anesthetist & \\
Endocrinologist & \\
Neurologist & \\
Radiologist & \\
Pain relief doctor & \\
Cardiologist & \\
Nephrologist & \\
Oncologist & \\
\hline
\end{tabular}

- The following measures should be adopted to prevent blistering:

$\checkmark$ the baby should not be placed systematically in an incubator unless needed for reasons such as prematurity [10]: heat and humidity can lower the threshold for blistering. An overhead heater can be used, cautiously regulated.

$\checkmark$ Naso- and oro-pharyngeal suction should be avoided. If required, a soft catheter is chosen, and minimal suction pressure exerted [31].

$\checkmark$ The umbilical cord should be secured with a ligature, avoiding the use of plastic clamps which rub the skin $[10,31]$.

$\checkmark$ The use of clips should be avoided, and name band put on clothing instead of wrist.

$\checkmark$ Electrodes should be of small size; the adhesive rim should be removed allowing only the lubricated central portion to be in contact with the skin and the electrode should then be secured with a non-adhesive dressing (e.g. Mepilex ${ }^{\circledR}$, Mölnlycke) [33].

$\checkmark$ Clip sensors should be used for pulse oximetry.

$\checkmark$ For blood pressure monitoring, thick padding is recommended before applying the blood pressure cuff. $\checkmark$ When possible, skin-to-skin contact (kangaroo care) with parents should be encouraged.

$\checkmark$ There is no contraindication to immunization for infectious diseases.

\section{Skin care}

- For clothing, a front-fastening babygro is easier to put on and remove. It should be turned inside out to prevent the seams from rubbing skin [31]. If available, DermaSilk (Alpretec) underclothes and gloves can be used as they combine silk properties with the protective activity of an antimicrobial agent, in addition to being seam-free. Alternatively, Tubifast (Mölnlycke) garments and gloves can be used [10].

- Disposable nappies can be used, they should first be lined with a soft material (e.g. soft silicone contact layer or foam such as Mepitac, Mölnlycke) in order to reduce skin rubbing from the elastic edges. Nappies with Velcro fasteners prove safer as it is less likely for the securing tapes to adhere to the skin [10,31].

- Particular attention should be paid to avoid friction when handling the baby: he/she should be nursed on neonatal incubator mattress, and lifted by sliding hands below the mattress or using the sheet [10]. To handle the naked infant, the nurse/caregiver should roll the baby away, place one hand behind his/her neck and head and the other one behind his/her buttocks, let the baby roll back and then lift him/her [31,32] (Figure 1).

- Adhesive tapes must be avoided. Soft silicone fixation tapes providing atraumatic removal (e.g. Mepitac ${ }^{\circ}$ ) are recommended to secure devices such as electrodes, catheters, tubes, and probes. For removal they should be rolled out gently rather than lifted.

- Silicone Medical Adhesive Removers (SMARs), such as Appeel (CliniMed) or Niltac, should be used to remove electrodes or accidentally applied tapes or dressing/clothing adhered to wounds. If SMARs are not available, liquid and white soft paraffin in equal parts facilitate atraumatic removal [10,34,35].

- Regular bathing in tepid to slightly warm water is recommended (Figure 1), the frequency will be adapted to each case. If the infant presents crusted lesions, an emollient/oil-based cleanser should be used, while infected wounds should be treated with an antiseptic (e.g. containing $0.1 \%$ chlorhexidine). After bathing, the skin should be dried by gentle padding with a towel.

- Diaper area cleansing should be performed with liquid and white soft paraffin in equal parts or with an emollient/oil-based cleanser [10,31].

- Principles for blister, aplasia cutis congenita and wound treatment are similar to those applying to children and adults (see paragraph "Wound care"). 


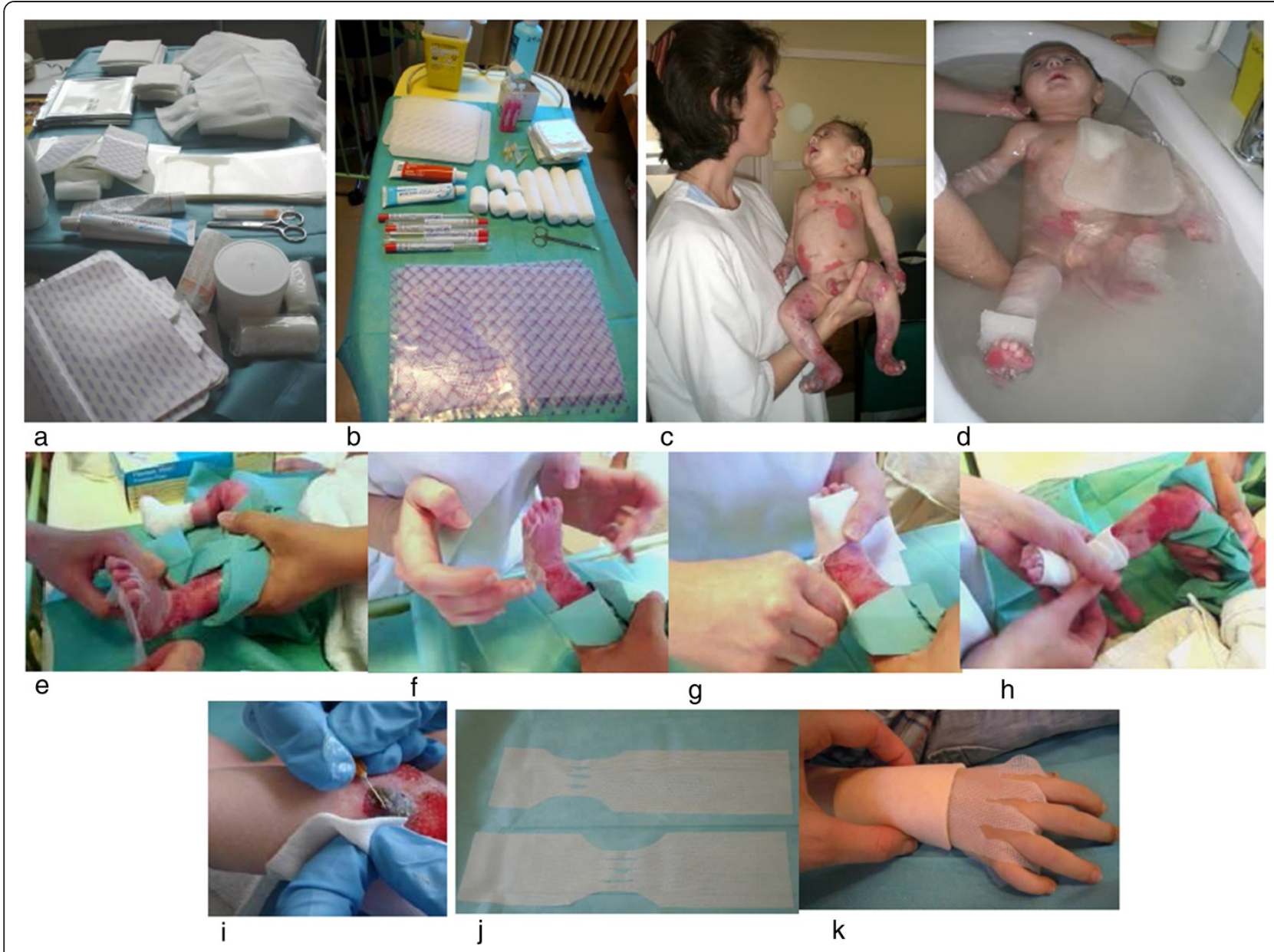

Figure 1 Inherited epidermolysis bullosa: wound care. $(\mathbf{a}, \mathbf{b})$ Dressing cart prepared in advance for patient dressing: soft silicone foams $(*)$, petroleum jelly $(<)$, emollient cream $(>)$, antimicrobial cream ( () , gauzes, tubular bandages, needles and swabs for culture ( $\nabla)$. (c) How to hold the baby: one hand behind the head and the other one behind the buttocks. (d) Bathing the baby also facilitates atraumatic removal of dressings which float into the water. (e-h) Wound care with non-adherent soft silicone dressings and thin polyurethane-soft silicone foams. (i) Lancing and draining of a haemorrhagic blister. (j-k) Soft silicone foams specifically modelled for hand dressing (j), and hand dressing to separate fingers and prevent early digit fusion (k).

- Aplasia cutis congenita and blistering involving hands or feet or digit degloving following delivery require specific dressing in order to prevent early digit fusion [10]. The separation should be performed by using easily modelled dressings, such as soft silicone foams (e.g. Mepilex ${ }^{\circ}$ or Mepilex Lite ${ }^{\circ}$, which are cut into strips (Figure 1). If advanced dressings are not available, paraffin-impregnated gauzes can be used, and should also be cut into thin strips. Attention should be paid to keep the first finger extended and separated from the rest of the hand.

- The diaper area is constantly subject to handling, exposed to urine, feces and to the diaper occlusion effect. We prefer to treat the less exuding erosions with paraffin-impregnated gauzes, replaced at each nappy change. Alternatively, a soft silicone primary wound dressing (e.g. Mepitel ${ }^{\circ}$ ) or hydrogel- impregnated gauzes (e.g. Intrasite ${ }^{\bullet}$ Conformable, Smith \& Nephew) can be used. In more exuding lesions, an antiseptic and silicone foams (e.g. Mepilex $^{\oplus}$ or Mepilex ${ }^{\oplus}$ Transfer) are indicated.

\section{Feeding modalities}

- In less severely affected newborns breast-feeding is possible: soft paraffin can be applied on the nipple and breast as well as on the infant face and lips to reduce friction from rooting reflex [31]. The mother should be trained to handle the baby and breast feed him. When breast-feeding proves traumatic, oral feeding remains the best option, also allowing to add supplements in malnourished infants.

- Commercially available teats should be softened with warm boiled water. The teat hole can be enlarged or 
extra holes may be created to facilitate sucking. Lips can be protected with petroleum jelly to avoid the skin sticking to the teat [31].

- A Haberman feeder reduces the sucking effort and its long teat avoids nose trauma from the bottle collar $[10,31]$.

- A few infants may require naso-gastric feeding. A small soft polyurethane tube fixed for few weeks will minimize internal damage and reduce the trauma [31].

- For nutritional principles see paragraph "Nutritional aspects".

\section{Follow-up}

- The infant should be discharged home when the general health condition is stable and the parents are adequately educated and confident to care for their baby. This decision is taken jointly by the dermatologist and neonatologist/pediatrician. The involvement of social workers and psychologists in the organization of the discharge is helpful.

- A first follow-up visit with a specialized team (usually: dermatologist, pediatrician, EB nurse, psychologist) will be organized in one or two weeks for severe EB subtypes (e.g. Dowling-Meara EBS, $J E B$ and recessive $\mathrm{DEB}$ ). It should comprise a complete clinical examination (skin/mucosae, nutrition, pain, etc.), dressing, and evaluate and pursue the therapeutic education of the parents. If the infant care is correctly performed the next appointment should be in one month, then every three months during infancy. In mild EB subtypes the follow-up visits will be every 3-6 months.

\section{EB care from childhood to adult}

Additional problems in skin and wound management during childhood to adulthood include, in particular in Dowling-Meara EBS, generalized forms of JEB and recessive DEB (RDEB) [4,5,12,13,17,36-38]:

- reduced patient compliance to care and claim for self-care;

- chronic pain;

- presence of chronic wounds and their susceptibility to infection;

- risk of cancer development;

- chronic itching;

- anemia and malnutrition secondary to oral and gastrointestinal involvement and chronic wounds, in turn negatively interfering with wound healing;

- psychological problems related to both disease acceptance and social relationship (school, hobbies, job, etc.).

\section{General principles}

- The members of multidisciplinary team vary upon the EB type and patient and family needs. In mild EBS subtypes (e.g. localized and generalized nonDowling-Meara EBS), the dermatologist ensures the follow-up with the help of a specialized nurse. In severe EBS forms (such as Dowling-Meara EBS or EBS with muscular dystrophy), JEB and generalized DEB subtypes the core members are the dermatologist and the pediatrician supported by the EB nurse and dietician. Other specialists (ophthalmologist, dentist, digestive surgeon, psychologist, physiotherapists, etc.) are involved depending on disease complications.

- A regular follow-up is required to evaluate skin and mucosal conditions, general health status, and specific problems encountered by the patient and his/her caregivers. Follow-up planning should be performed taking into account the EB type, disease complications, family and patient compliance and specific complains. After childhood, EBS and mild DEB patients are generally seen by an EB specialist once a year; JEB and generalized RDEB should be seen at least twice a year. More frequent follow-up visits (e.g. every month) are required for the most severe patients in order to fasten wound healing and to early diagnose and treat squamous cell carcinoma.

\section{General measures}

- Monitoring of severe EBS variants (e.g. DowlingMeara EBS or EBS with muscular dystrophy), JEB, and generalized RDEB subtypes comprises at followup visits: a complete blood count, electrolytes, total serum protein and albumin, iron, iron-binding capacity, ferritin, erythrocyte sedimentation rate, Creactive protein, liver function tests, urea, creatinine and, if required, zinc, selenium, folate and vitamins (A, $B_{6}, C, D$ and E) $[22,39]$. Swabs for culture should be taken from infected and critically colonized wounds, as blood cultures in case of sepsis suspicion.

- Patient adherence to therapy should be regularly checked. Caregiver and patient compliance and experience should be always taken into account in designing the care plan.

- Immunization schedule for infectious diseases should be regularly continued. Chicken pox vaccination is recommended.

- Preventive measures to reduce the onset of new lesions are summarized in Table 4 [10,31,32,40]. 


\begin{tabular}{|c|c|}
\hline \multirow[t]{5}{*}{ Direct skin protection } & $\begin{array}{l}\text { - Protect vulnerable skin sites, (e.g. knees and elbows) with soft silicon contact layers, silicon sheets or strips (e.g. KerraPro }{ }^{\oplus} \text { ) } \\
\text { or thick padding }\end{array}$ \\
\hline & - Use gloves when the child begins to crawl/walk and lifelong during sports or hobbies (e.g. DermaSill ${ }^{\circledast}$ or Tubifast ${ }^{\oplus}$ ) \\
\hline & - Avoid hard shoes with internal seams, tight clothes and clothes with raised seams, tags in contact with the skin \\
\hline & - Use protective padding for shoes, such as a poron insole or orthotic device \\
\hline & - Pad the frame at the nose bridge and over the ears of eye glasses \\
\hline \multirow[t]{3}{*}{ Other measures } & - Ensure that toys are frequently cleaned and in soft material without traumatic angles \\
\hline & $\begin{array}{l}\text { - Prefer hobbies and sports at low risk of skin trauma (e.g. adapted gym, swimming, ping-pong, reading, singing, playing } \\
\text { music, electronic toys and informatics) }\end{array}$ \\
\hline & - House air conditioning and other cooling measures in hot climates \\
\hline
\end{tabular}

\section{Skin care}

- Regular patient follow-up by the dermatologist comprises the assessment of the entire body including the scalp, external ear, genital/anal area, oral cavity and nostrils.

- A dermatological management is necessary in all types of EB and skin lesions.

- An appropriate analgesia should be performed before any procedure, such as bathing or dressing (see paragraph "Pain management").

- For the hygiene, a mild antiseptic cleanser (e.g. chlorhexidine $0.1 \%$ or polyhexanide, sodium hypochlorite $5-10 \mathrm{ml}$ in $5 \mathrm{~L}$ of water, acetic acid $\leq 0.25 \%$ ) should be used for extended and/or critically colonized/infected lesions [39,41]. An emollient/oil-based cleanser should be chosen for xerotic skin and hyperkeratotic or crusted lesions.

- Bathing frequency depends on the type of dressing and lesion characteristics: in case of infected wounds or dressings which stick to the lesions (e.g. paraffinimpregnated gauzes) bathing should be performed every other day; when advanced dressings are employed bathing can be delayed until once a week.

- New blisters should be lanced (finger prick lancet, sterile large-bore needle or scalpel blade) (Figure 1) and drained. The blister roof should be left in place to facilitate re-epithelialization, to reduce infection risk and pain [10,31,32,42].

- Daily use of emollients and moisturizing products is strongly recommended for xerotic skin in order to reduce blistering, pain and itching [31].

- Regular photoprotection is mandatory in patients affected by KS who present photosensitivity.

- Courses of topical keratolytic agents (e.g. urea, salicylic acid, ammonium lactate) are helpful to treat palmoplantar hyperkeratosis and/or keratoderma [40]. Their concentration depends on the patient age, rhythm of application, treatment duration and local tolerance. Particular caution is required for young children.

- Hyperhidrosis, frequent in EBS patients, should be treated in order to reduce/prevent blistering and itching. Corn flour is an inexpensive and easily available remedy [10,40], other absorbent powders (e.g. Zeasorb ${ }^{\circ}$, Stiefel Laboratories) may also be useful. An additional option is iontophoresis [43]. Furthermore, the use of botulinum toxin may be considered for severe plantar hyperhidrosis [43,44]. Silver-lined or Dermasilk socks keep feet dry and comfy, provide anti-friction action and reduce the risk of bacterial overgrowth $[10,40]$.

- EB nevi should undergo a regular clinical and dermoscopic follow-up [11]. Although a slightly increased risk of melanoma has been reported only for RDEB, atypical pigmented lesions undergoing significant morphological changes should be biopsied [45 and references herein].

- No specific treatment is required for milia.

- Mucosal care:

- Oral management should adhere to the recently published best practice guidelines for oral health care in EB [9].

- Conjunctiva should be regularly lubricated, in particular in JEB or RDEB patients, with lanolin and preservative-free eye drops or gels, e.g. containing hyaluronic acid, polyethylene/ propylene glycol or carbomer [45].

- Nasal lubricants are more frequently indicated for JEB or RDEB patients; regular ointment containing vitamin $\mathrm{E}$ or simply petroleum jelly can be helpful.

\section{Wound care}

The choice of dressings varies upon the type and site of the lesions, but also product availability $[8,10,42,46,47]$. Advanced dressings delay the frequency of dressing change, thus reducing pain and manipulation-related risk of blistering and infections. In addition, non- 
adherent dressings proved superior in reducing pain at dressing removal. However, systematic literature reviews showed only a modest advantage for advanced dressings (e.g. hydrogels, hydrofibers and foams) compared to paraffin-impregnated gauzes in accelerating healing of non-EB chronic wounds (venous leg ulcers, pressure sores, etc.) [48]. As to topical antibiotics and antiseptics, their role in healing of leg ulcers remains to be proved [49]; there is a good evidence of their usefulness for the treatment of superficial skin infections [50]. The debridement of the wounds is important to accelerate the healing process and to prevent infection: some dressings such as hydrogels, polymeric membranes and hydrofibers are helpful $[8,10,46,47]$. In case of multiple and deep necrotic lesions, mechanical debridement should be performed gently in the theatre with analgesia.

\section{Dry to lightly exuding wounds}

- Non adhesive soft silicone or lipido-colloid contact layers [e.g. Mepitel ${ }^{\oplus}$, Adaptic ${ }^{\oplus}$ touch (Systagenix), Urgotul $^{\odot}$ (Urgo Medical), Silflex ${ }^{\oplus}$ (Advancis Medical)], thin polyurethane-soft silicone foams (e.g. Mepilex ${ }^{\odot}$ Lite), and hydrogels (e.g. Intrasite ${ }^{\varpi}$ Conformable) appear to be the most suitable in these lesions $[8,10,46,51]$. Hydrogel dressings should be changed daily or as soon as they become dry. The other types could be changed every 3-4 days.

- The dressing choice depends on the affected site: e.g. flexible dressings should be used mainly for the folds. Soft bordered materials [e.g. Mepilex ${ }^{\odot}$ Border, Alleyvn ${ }^{\bullet}$ Gentle Border (Smith \& Nephew)] easily adapt to the different skin sites but they may be too sticky and thus require a primary contact layer in order to protect fragile skin [10].

\section{Heavy exuding wounds}

- Heavy exuding wounds present a high risk of infection and require specific dressings. Either hydrofiber dressings (e.g. Aquacel ${ }^{\bullet}$, Convatec) or soft silicone foam with super-absorbers (e.g. Cutimed $^{\oplus}$ Siltec, BSNmedical), able to absorb the abundant exudates, should be preferred. Soft silicone foams [e.g. Mepilex ${ }^{\oplus}$, Mepilex ${ }^{\oplus}$ Transfer, and Advazorb Silflo (Advancis Medical)] and polymeric membranes (PolyMem ${ }^{\oplus}$, Ferris Mfg. Corp.) are also indicated $[8,10,46,51]$. The soft silicone foams are also suited for digits and folds. On the other hand, PolyMem ${ }^{\odot}$ is not easily retained on the wounds and requires a secondary dressing to hold in place. Also Mepilex ${ }^{\oplus}$ Transfer needs a secondary dressing to absorb exudates.

\section{Critically colonized and infected wounds}

- To early diagnose a critically colonized or infected wound the following parameters and features should be considered:

$\checkmark$ wound history: several week duration, recent size extension and exudate increase;

$\checkmark$ wound bed: presence of debris, dead slough, friable tissue and bad smelling;

$\checkmark$ wound margins and surrounding skin: oedema, erythema, higher temperature than the healthy skin.

- In the presence of the above mentioned criteria, swabs for culture should be taken after washing the lesion with normal saline and then the treatment should be started based on clinical features [41].

- Wounds should be cleaned with mild antiseptics, such as chlorhexidine $0.1 \%$ or polyhexanide, sodium hypochlorite at a concentration of 5-10 $\mathrm{ml}$ in 5 liters of water, or acetic acid at $\leq 0.25 \%$ for 15-20 minutes/day $[39,41]$.

- In case of lesions at risk of infection, the use of lipid-stabilized hydrogen peroxide cream (Crystacide ${ }^{\circledast}$ ) has been proposed [41]. An aqueous solution of eosin (2\%) is employed in some countries with the aim to reduce the exudate, keeping in mind that it has no antiseptic properties. In other countries, medical-grade honey in ointments (e.g. Mesitran $\mathrm{S}^{\oplus}$, Medloc) or dressings (e.g. Algivon ${ }^{\oplus}$ Advancis Medical; Medihoney $^{\oplus}$, Derma Sciences) are available and used with the aim to reduce the risk of infection and promote wound debridement $[10,41,52,53]$.

- The use of silver-containing creams (e.g. silver sulfadiazine) or dressings (e.g. Mepilex ${ }^{\oplus} \mathrm{AG}$; Urgotul $^{\oplus}$ silver/SSD; PolyMem $^{\oplus}$ silver, Aquacel ${ }^{\circledR} \mathrm{Ag}$ ) has been advocated [10,41]. However, there is no clear evidence that silver-containing products can prevent wound infection or improve healing rates of leg ulcers [52 and references herein]. Importantly, silver plasma level should be checked in case of large surface and/or prolonged treatment because of the risk of silver absorption and related toxicity $[54,55]$. In children, the use of silvercontaining products should be very limited in time and treated surface.

- The dressings for infected wounds are the same used for heavy exuding wounds, but they should be changed daily.

- Principles for the use of topical and systemic antibiotics/antimicrobials are summarized in Table 5 $[8,41,56]$. 


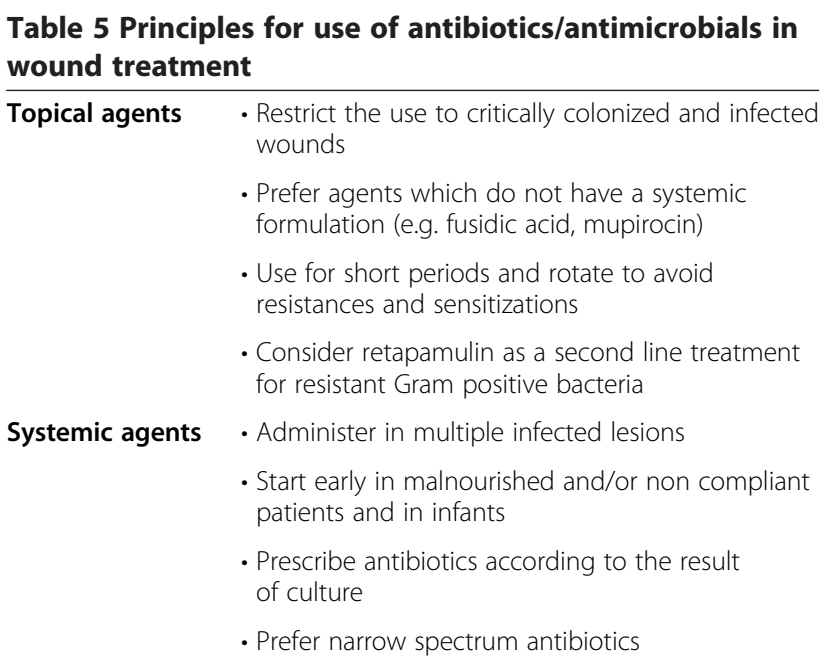

\section{Hyperkeratotic and crusted lesions}

- Warty and crusted lesions require an accurate treatment and follow-up because they are itchy and can mask an underlying squamous cell carcinoma. The crusts and hyperkeratosis should be regularly removed. Frequent application of emollient creams and bathing twice a week are indicated to this purpose.

\section{Exuberant granulation tissue}

- Short courses of very potent topical glucocorticoid ointments are reported as effective in reducing the exuberant granulation tissue frequently observed in JEB $[8,10]$.

\section{General remarks}

- The dressings of all types of wounds should be checked daily and the change frequency modified based on wetting and smelling.

- Paraffin-impregnated gauzes (e.g. Jelonet ${ }^{\circ}$, Smith \& Nephew) or medicated gauzes (e.g. Fitostimoline ${ }^{\circ}$ containing an aqueous extract of Triticum vulgaris, or Connectivine ${ }^{\bullet}$, Fidia, containing hyaluronic acid) can be used when advanced dressings are not available $[8,10]$. They require a secondary dressing and should be changed on a daily basis, increasing wound manipulation, pain and indirectly also the risk of infection. These products adhere to the wound bed. In order to reduce pain and trauma, dressing removal requires prolonged soaking with distilled water or saline solution or bathing $[8,10]$.

- In RDEB patients, finger and toe dressing should be regularly performed as described for the neonatal period, to delay digit fusion and pseudosyndactyly [10].

- Tubular bandages of various sizes and heights according to the affected body area (e.g. Elastomul', Tubifast ${ }^{\circ}$ or Self-fix ${ }^{\circ}$ ) should be used for dressing retention to prevent slipping and further trauma. Tight bandages must be avoided as they can induce blistering by rubbing the skin $[8,10]$. If available, Dermasilk $^{\bullet}$ or other specifically designed garments, without silver, can also be useful to retain the dressings in place.

\section{Itch management}

Itching is common in EB patients with dry/atrophic skin, multiple warty lesions, during late phase of wound healing, or following sensitization to topical treatment. Pruritus may also develop in the absence of an identifiable etiology $[8,10]$. Itching is frequently chronic, severe and unresponsive to conventional treatments. Furthermore, a rare subtype of DEB, DEB pruriginosa, is characterized by onset of severe and unremitting pruritus from infancy to adulthood [57,58]. Itch-induced scratching damages the skin, thus increasing blistering and susceptibility to infection. General measures and therapeutic options to manage itch are summarized in Table 6 [8,10,59-64].

\section{Management for surgical procedures General principles}

- Surgery in general anaesthesia should be limited to strictly necessary procedures and organized jointly

Table 6 Chronic itch management

\begin{tabular}{|c|c|}
\hline \multirow[t]{3}{*}{ General measures } & - Bathing in tepid water with syndet/oil cleanser and skin hydration with emollients \\
\hline & - Overheating and dry environment avoidance \\
\hline & - Relaxation techniques and patient education to cope with the vicious itch-scratch cycle \\
\hline \multirow[t]{4}{*}{ Therapeutic options } & - Short courses of topical mid-potency steroids \\
\hline & $\begin{array}{l}\text { - Sedating antihistamines (e.g. hydroxyzine) and/or tricyclics with anti-H1 antihistaminic action (doxepin) as first-line } \\
\text { treatment* }\end{array}$ \\
\hline & - Low-dose gabapentin (Neurontin ${ }^{\oplus}$ ) or pregabalin (Lyrica $\left.{ }^{\oplus}\right)$ as second-line treatment \\
\hline & $\begin{array}{l}\text { - Anti-inflammatory agents (e.g. cyclosporine, thalidomide or topical tacrolimus) to be cautiously considered as third-line } \\
\text { treatment only in severe cases** }\end{array}$ \\
\hline
\end{tabular}


by the surgical team (surgeon, anaesthesiologist and nurse) and the EB team coordinator.

- Whenever necessary and feasible, the different surgical treatments should be performed at one time in order to reduce the risks linked to anaesthesia.

- A tailored management should be planned for each patient after a careful evaluation.

\section{General measures}

- When a surgical procedure in general anesthesia is planned, a multidisciplinary re-assessment should be performed a week or two ahead of the surgery date to verify the general health conditions of the patient [33].

- Blood sampling should be performed before surgery to evaluate and treat anemia.

- Before the procedure, the surgical team, including the anaesthesiologist and the case manager, should clearly explain the possible problems and complications linked to the procedure, paying particular attention to those related to EB disease.

\section{Specific measures}

- Anxiolytic administration can be helpful in the preoperative stage.

- The measures to be adopted in the operating theatre are summarized in Table 7 [33-66].

- After surgery, the intravenous line should be kept in place as long as possible to be used for transfusion, perfusion or other systemic therapy (iron, albumin, antibiotics).

- Fiberoptic intubation appears to be a good technique to minimise frictional trauma and to reduce the risk of blistering, whilst safely securing the difficult airway [67].

\section{Pain management}

Pain is constant in EB patients since birth, and its management is a major therapeutic focus conditioning the daily care. A tailored approach should be planned for each patient considering the different types of pain, and the treatment efficacy should be evaluated regularly.

Table 7 Patient management in the operating theater

\begin{tabular}{|c|c|}
\hline Procedure & Measures to be adopted \\
\hline \multirow[t]{3}{*}{ Operating table } & - Place an anti-decubitus mattress and cushion on the table \\
\hline & - Use the sheet to lift the infant and move him/her to the operating table; older patients should move themselves \\
\hline & - Pad trauma-exposed sites (e.g. chin, occiput, elbows, heel, hands, feet) \\
\hline \multirow[t]{7}{*}{ Premedication } & - Administer oral premedication 45 minutes prior surgery in order to reduce/prevent: \\
\hline & $\checkmark$ Patient anxiety (midazolam 0.5 mg/kg) \\
\hline & $\checkmark$ Oral secretion (atropine 40 mcg/kg) \\
\hline & $\checkmark$ Gastro-esophageal reflux (ranitidine $1 \mathrm{mg} / \mathrm{kg}$ ) \\
\hline & $\checkmark$ Vomiting (metoclopramide 150 mcg/kg) \\
\hline & $\begin{array}{l}\text { - Prefer intravenous induction in presence of intravenous line, otherwise inhalational anaesthesia. In the latter case, } \\
\text { protect the face from the mask with silicon foam (e.g. Mepilex }{ }^{\oplus} \text { ) or a water-based lubricant. }\end{array}$ \\
\hline & - Protect the eyes with a moisturizing ophthalmologic gel and the eyelids with moistened gauzes \\
\hline \multirow[t]{8}{*}{ Patient monitoring } & - Use tape with a silicon contact layer (Mepitac $\left.{ }^{\oplus}\right)$ to fixe all tubes (e.g. endotracheal tube) and catheters \\
\hline & - Lubricate all tubes with a water-based lubricant \\
\hline & $\begin{array}{l}\text { - Remove the adhesive part of electrodes allowing only the lubricated central portion to be in contact with the skin; } \\
\text { then secure with a non adhesive dressing (e.g. Mepilex }{ }^{\oplus} \text { ) }\end{array}$ \\
\hline & - Use clip sensors for pulse oximetry \\
\hline & - Use a lubricated disposable thermometer \\
\hline & - Pad the skin with cotton or advanced dressings under the blood pressure cuff \\
\hline & - Use bipolar diathermy to avoid a monopolar pad \\
\hline & - Avoid carefully all kinds of trauma and friction for the entire duration of surgery \\
\hline \multirow[t]{2}{*}{ Intubation } & - Evaluate microstomia, esophageal strictures and prominent incisors in $\mathrm{RDEB}^{*}$ patients who need intubation \\
\hline & - Prefer fiberoptic-assisted intubation to laryngoscopy in case of difficult intubation \\
\hline \multirow[t]{2}{*}{ Recovery room } & - Administer a moderate sedation before emergence to avoid cutaneous lesions due to irritability \\
\hline & - Perform tracheal aspiration gently using soft and small tubes \\
\hline
\end{tabular}




\section{General principles}

- Pain is acute, chronic and related to procedures (e.g. bathing, dressing, surgical procedures, etc.). Psychological pain and anxiety contribute constantly to worsen organic pain.

- Acute pain is mainly due to newly-onset mucosal lesions (cornea, oral cavity, oesophagus, anus or larynx and trachea).

- Chronic pain includes inflammatory, neuropathic and bone pain.

- The general conditions and nutritional status affect the severity of chronic pain.

- Evaluation of pain is mandatory and should address all the above mentioned components. It can be difficult in particular in children. Pain evaluation scales and frequency are the same used for non-EB patients and vary according to the patient age and on-going procedures.

- An EB expert should examine and listen attentively to the patient and his family in order to design the individual therapeutic strategies.

- An early adequate management of the physical pain is mandatory in order to reduce also the psychological pain component and to promote patient compliance.

- An early and regular psychological support for patients and families can contribute to the global efficacy of pain management.

- Unfortunately, in some cases, both pharmacological and psychological management strategies do not achieve complete pain control.

\section{General measures}

\section{Pain related to nursing procedures}

- Bathing and dressing should be performed in a room equipped with all the necessary materials prepared in advance and close at hand (Figure 1). Non-pharmacological treatments based on cognitive-behavioural techniques are essential. A quiet and relaxing environment is helpful (music, films, pacifier dipped in glucose solution, etc.). The caregiver should provide contact, caresses and sweet words. Hypnosis can be useful in older children and adults.

- The choice of pharmacological treatment depends on the patient age, psychological status, type and severity of pain and planned procedure. The time of drug administration before the procedure varies according to the type of drug and route [68-73].

- Topical anaesthetics (xylocaine, lidocaine-prilocaine) are recommended before the care of painful tense blisters or wounds and venipuncture. However, the total dose should be limited to prevent the risk of seizures and methemoglobinemia.

- Paracetamol is the first choice for mild pain and short procedures. In more severe pain and complex procedures, opioids are indicated (from codeine to oxycodone and morphine). Opioid side effects include constipation, pruritus and rarely respiratory failure. The development of tolerance leads to dose increase with risk of addiction [70-74].

- Hydroxyzine and midazolam can be associated to analgesics to reduce anxiety and for short sedation. More rarely, ketamine is also used, particularly in children $[75,76]$.

- Meopa ${ }^{\oplus}$ (nitrogen monoxide-oxygen mixture) can be helpful in most severe pain both in children and adults. Its use is restricted to the hospital setting and limited in time.

\section{Chronic pain}

- General measures are essential (e.g. music, yoga, relaxation techniques, hypnosis, etc.). In most cases, they need to be combined with analgesics.

Paracetamol is usually the first-line treatment, followed by opioids (codeine, morphine, etc.). Non steroid anti-inflammatory drugs (NSAID) should be cautiously administered in patients with chronic/ severe infections.

- A neuropathic pain component can be managed with pregabalin $\left(\right.$ Lyrica $\left.^{\circ}\right)$ or gabapentin (Neurontin ${ }^{\odot}$ ) [73]. Tricyclic antidepressants, e.g. amitriptyline, are an alternative treatment.

- The daily analgesic dose should be distributed over 24 hours and increased before any care procedure.

- Bone pain, usually observed in severe RDEB, is due to abnormal bone mineralization, in turn related to poor nutrition, reduced mobility and chronic inflammation. Therefore, the improvement of nutritional status and physiotherapy contribute to reduce pain. Biphosphonates are useful to decrease bone pain, but their administration can be limited by perfusion difficulties and side effects (e.g. mandible osteonecrosis).

\section{Acute pain}

- Reassure the patient and his family.

- Administer adequate analgesic therapy (frequently opioids) or increase the dose of the ongoing treatment.

- Local anaesthesia may be useful in case of painful constipation due to anal erosions or fissures. Botulinum toxin for anal sphincter relaxation may represent a valid alternative. 


\section{Psychological pain}

- Acute and chronic pain induce psychological pain since the first days of life.

- An inadequate pain control during procedures may cause a vicious circle with a memorization of the physical pain, and then anticipation and psychological distress increasing the physical pain at each procedure. Relaxation techniques, psychological support and pharmacological treatment should be provided.

- Psychological support should be reinforced during adolescence. A latent depression is not exceptional in the most severe forms and appropriate treatments have to be administered.

\section{Nutritional aspects}

Growth and nutritional condition are major outcomes in EB patient care. Nutrition is often a real challenge. Blisters and erosions affecting oropharynx and oesophagus cause pain and dysphagia, followed by microstomia, ankyloglossia and tooth decay in severe RDEB. Altogether these manifestations contribute to reduce oral intake. Recurrent blistering can also lead to strictures and even complete oesophageal obstruction which are usually managed by endoscopic dilation [77-79].

On the other hand, protein-calorie and micronutrient needs are increased by (i) accelerated skin turn-over, (ii) blood and protein losses through skin wounds, (iii) recurrent infections, and (iv) chronic inflammation. Micronutrient deficiencies (iron, zinc, selenium, vitamins, etc.) can lead to severe complications. Iron, folate and vitamin $B_{12}$ deficiencies contribute to multifactorial anemia typical of severe RDEB and JEB. Other nutrient deficiencies (carnitine, selenium) might play a role in inducing cardiomyopathy. In addition, an insufficient fluid and fibre intake frequently causes constipation, which can induce painful defecation (anal fissures). Overall, nutritional compromise is more important in generalized forms of RDEB and JEB [80-82].

Unfortunately, an improvement of nutrition in severe EB subtypes is usually not associated with a significant amelioration in wound healing rates. Nevertheless, an appropriate nutritional management is necessary since infancy also to promote pubertal development.

\section{General principles}

- The evaluation of patient growth, performed according to international standards (weight for length $<2$ years; body mass index $>2$ years), can be hampered by fixed contractures.

- The nutritional support should start early, especially in severe generalized subtypes.
- Dietetic advices, aimed to increase energy and protein content of oral food, should be addressed continuously to patients and their families.

- All factors affecting the quality of nutrition need careful management and follow-up: trauma related to hard food, dental caries and periodontal inflammation, gastro-oesophageal reflux, oesophageal strictures, inflammatory bowel disease, anal fissures and constipation, etc.

\section{General measures}

- Proteins and energy

Conventional dietetic approaches using oral highenergy and high-protein semi-liquid supplements rarely provide sustained improvement of dietary intake in severe EB forms. Consequently, children who survive without nutritional support become thin and short adults. A specific Tool to Help Identify Nutritional Compromise (THINC) in EB has been designed. The suggested nutritional requirements reach about $100-150 \%$ of the recommendations for healthy age- and gender-matched children for energy and $115-200 \%$ for proteins [81].

\section{- Micronutrient requirements [81-87]}

Evaluation of iron needs is frequently hampered by chronic inflammation. Daily intake of iron is recommended in case of hypochromic microcytic anemia; however it is often associated with gastric irritation, diarrhea or constipation. If oral supplementation is not tolerated and/or insufficient, intravenous administration (Venofer ${ }^{\circ}$, Ferinject ${ }^{\circ}$ ) should be considered and its frequency adapted to each patient. The use of erythropoietin or darbepoetin alfa in combination with iron supplementation has been proposed [85]. Vitamin requirements should be evaluated considering the disease type and patient age. In more severe forms, vitamin (A, $C, D, E)$ levels should be checked at least once a year. Vitamin C supplementation is useful to enhance iron absorption. Vitamin D and calcium supplementation are needed to prevent/treat osteoporosis. Zinc, carnitine and selenium levels should be evaluated at least once a year in the most severe forms [88].

\section{- Nutritional procedures: nasogastric and gastrostomy feeding}

Nasogatric feeding can induce internal friction, irritation of nostrils and hypopharynx or oesophageal erosions. Therefore it should be used only for short periods in presence of severe oral cavity and pharyngeal blistering. The tube should be soft and of small size. 
Gastrostomy feeding (GTF) has been shown to be welltolerated and to improve patient nutritional outcome, growth and puberty. It should be performed in patients unable to feed orally (e.g. very severe and chronic oral lesions or oesophageal strictures not susceptible to dilation treatment) and/or presenting loss in weight and height of at least 1 standard deviation compared with their best growth level, despite regular nutritional advice. Starting GTF before malnutrition onset also reduces the problems linked to the choice of the button device and to the insertion site dehiscence [89-91]. A regular surveillance is necessary in order to prevent and/or early treat the possible local complications (chronic wound and infection).

The rhythm and rate of GTF delivery, volume, energy intake and formula concentration should be adapted to individual needs and tolerance and to patient and family lifestyle. The use of anti-secretory and anti-acid drugs (e. g. ranitidine or proton pump inhibitors) is recommended to treat gastro-oesophageal reflux and also to prevent skin damage due to gastric acid leakage at gastrostomy site [91]. GTF also easies the supply of micronutrients (iron, zinc, selenium, vitamins), nutritional supplements or drugs.

Oral feeding and swallowing skills should be continuously encouraged while using GTF. The patient should participate to "familial life" and familial meals. In all cases, a psychological support is essential. After the achievement of puberty development gastrostomy can be removed, provided a sufficient oral nutrition and absence of intractable oesophageal strictures. Unfortunately in JEB-Herlitz, GTF is not successful and thus not recommended in the context of palliative care [92].

\section{Physical therapy and rehabilitation}

Physical and occupational therapy must be started early in life in particular in EBS with muscular dystrophy, generalized RDEB and JEB subtypes. The continuing work on muscles and joints delays contractures and deformities, improves functional mobility, enhances patient autonomy and, ultimately, promotes social inclusion. Static (preventive) and dynamic (corrective) orthosis, directed therapeutic exercises and recreational activities are powerful tools. Some forms of physical medicine, such as hydrotherapy, are also useful $[93,94]$.

\section{Early diagnosis of squamous cell carcinoma (SCC)}

SCC represents one of the major complications of EB, in particular generalized RDEB subtypes and, less frequently, generalized non-Herlitz JEB [5,12]. It occurs more often from the third-fourth decade of life. SCC usually arise in areas of chronic wounds and scars. The clinical presentation is frequently atypical with warty or ulcerated appearance. An early diagnosis is mandatory and literature data highlight that a diagnosis delay implies a poor prognosis.

In order to ensure an early diagnosis, it is necessary to perform [95]:

- whole-body physical examination, including the scalp, oral mucosa and genital area, every 6 months in RDEB and adult JEB patients;

- more frequent follow-up in presence of chronic hyperkeratotic or warty wounds;

- multiple excisional biopsies in case of crusted-warty skin lesions or chronic wounds unresponsive to proper treatments;

- early and wide excision of the lesion in case of histologically confirmed carcinoma.

\section{Management of intercurrent or associated cutaneous diseases}

A few reports describe cutaneous infectious diseases occurring in EB patients, and even fewer data exist about associated chronic inflammatory diseases (psoriasis, atopic dermatitis, etc.) [96-99].

Skin diseases, when manifesting in EB patients, can:

- represent a diagnostic challenge due to atypical presentation (impetigo, scabies, etc.);

- worsen EB course, due to the development of pruritus and risk of infection (e.g. atopic dermatitis, scabies, VZV infection, impetigo, etc.);

- need an adapted management which should take into account the presence of EB lesions and the increased risk of percutaneous absorption. Some topical products may indeed cause irritation and toxicity (e.g. topical treatment for cutaneous parasitic infestations, such as benzyl benzoate, permethryne).

When dealing with these intercurrent/associated diseases, the principles for diagnosis and therapy are:

- Pruritus onset/worsening in EB patients should foster investigation for parasitic infestation such as scabies and lice.

- Pruritus in associated cutaneous diseases should be treated as described for pruritus in EB patients (Table 6) in order to prevent worsening of EB lesions.

- Ivermectin represents a valid alternative to standard topical treatment for parasitic infestations in EB patients with generalized disease $[96,97]$.

\section{Therapeutic patient education}

Therapeutic patient education, as defined by the World Health Organization (WHO), is a continuous process of patient-centered medical care, enabling patients affected 
by chronic diseases, and their families, to better manage their illness [100]. Patient education has been shown to also contribute to prevent complications and to improve quality of life (QoL).

Despite the lack of controlled studies, patient education is unanimously considered extremely important also for EB patients and their caregivers.

Table 8 summarizes the principles and measures of therapeutic patient education applied to EB.

\section{Care of disease burden}

EB has a major impact on the QoL of the patient and his family, starting since birth when the baby diversity is immediately perceived by the parents and the transmitted notion of skin fragility can hamper the development of normal affective relationships within the family. Isolation, fear or insecurity about infant care, breastfeeding, where to go for help, role adjustment, fatigue, relationship with siblings or partners, body image, nutrition, and the need for peer support - all must be dealt with [101-107].

Specific problems can then manifest at every age, they range from the patient perception of his diversity to disease limitations in daily life and challenges related to social integration. Coping with continuous pain and consciousness of disease worsening represent major challenges for these patients and their families, in particular in severe disease forms.

\section{General principles}

- Whenever possible, the transfer of the newborn to the centre of expertise should be performed when also the mother is able to move, avoiding disruption of the close parent-infant relationship or even the infant refusal.

- A gradual and multistep delivery of information on diagnosis and prognosis can reduce the psychological trauma. Particular caution should be taken to avoid culpability feelings in the parents.

- The involvement of both parents in the education process may facilitate their coping with the disease, reduce couple difficulties and reinforce their relationship.

- The parents should be accompanied in the educational process of the affected child, at the same time ensuring that the child progressively acquires as much autonomy as possible.

- The participation of the entire family can reduce the risk that non affected siblings feel neglected by the parents.

- A psychological support to the patient and his family is frequently needed and should be integrated in the multidisciplinary management process.

- Monitoring of the emotional status of the patient and/or his family and early diagnose psychological distress require yearly appointments with a psychologist even in absence of specific symptoms.

- Specific instruments should be used for evaluation of psychological status and QoL [108-110].

- The psychologist should be involved early when the newborn parents manifest signs of persisting distress.

- Indications to the provision of psychological and psychotherapeutic support to the patient and family members are summarized in Table 9.

\section{Continuity of care}

A well-organized and structured continuity of care is important in EB like in all chronic and rare diseases. Following hospital discharge, EB patients require social support and medical assistance for EB-related and nonrelated problems. The center of expertise stays as the main structure offering specialized care to EB patients and, at the same time, should ensure an adequate liaison with the community healthcare system. Public health

Table 8 Patient education in epidermolysis bullosa: principles and contents

\begin{tabular}{ll}
\hline Principles & - Should be addressed to the patient, his/her family and caregivers \\
& - Should be delivered individually or in group \\
& - Should be adapted to the EB subtype, patient age, socio-cultural milieu and compliance \\
& - Should be delivered by specialized nurses with the support of the members of the multidisciplinary team and the psychologist \\
& - Should be performed orally and gradually, complemented by the release of information sheets for the patient and his/her family/caregivers \\
- Should at first clearly communicate the diagnosis, disease course and complications \\
• Should give clear explanations on the need of an adapted genetic counselling \\
- Should train the patient and his/her family/caregivers on the management of cutaneous and extracutaneous manifestations \\
- Should educate the patient and his/her family/caregivers to early recognize infection signs and atypical aspects of the chronic \\
wounds, and to consequently request a rapid evaluation by a dermatologist \\
• Should provide training on the life style in order to prevent disease worsening
\end{tabular}


Table 9 Indications to psychological or psychotherapeutic support to the family member(s) and patient

\begin{tabular}{|c|c|}
\hline \multirow[t]{7}{*}{ Family members } & - Fear to breastfeed or handle the newborn and/or infant refusal \\
\hline & - Lack of self-confidence or inadequacy feeling in coping with the disease \\
\hline & - Anxiety to be left alone with the disease \\
\hline & - Depression or disease refusal by one the two parents \\
\hline & $\begin{array}{l}\text { - Altered relationship of the couple (e.g. lack of interest in carrying out activities as a couple, loss of intimacy, negative impact } \\
\text { on sexuality, etc.) }\end{array}$ \\
\hline & - Culpability feelings and inability to take care of the non-affected children \\
\hline & - Discomfort feelings or depression of the siblings \\
\hline \multirow[t]{6}{*}{ Patient } & - Stress or depression related to the visibility of disease manifestations and the feeling of being different \\
\hline & - Chronic pain exacerbated by daily care procedures \\
\hline & - Chronic itching resistant to therapy \\
\hline & - Stress or depression due to limitations in daily activities and social life \\
\hline & - Lack of compliance and adherence to treatment, particularly in \\
\hline & - Adolescence and adulthood \\
\hline
\end{tabular}

and support services, both professional and peer, vary greatly country by country and even within the same country region by region. Nevertheless, some general rules can be drawn. At hospital discharge:

- a detailed referral form must be delivered and addressed to the primary care physician (pediatrician or general practitioner). It must report the diagnosis and the care given during hospitalization, describe the treatment plan for patient home care, the follow-up schedule and report the contact details of the EB team coordinator or his/her delegate from the center of expertise (e.g. specialized nurse) and, whenever available, of hotlines/call centres for emergency or urgent professional information;

- whenever foreseen by national laws, a certificate stating the diagnosis and a treatment plan must be addressed to the relevant public health authority in order to ensure free-of-charge care and provision of needed drugs, dressings and devices;

- depending on the national laws, ad hoc certificates must also be addressed to the public health service in order to guarantee homecare by specialized nurses, and if necessary also psychological support, physical therapy, occupational therapy, assistance by social workers, etc.;

- in countries where specialized EB nurses are not available, ad hoc training of the community health nurses is recommended;

- information sheets should be provided to the family/ caregiver (relatives, friends, teachers, colleagues, etc.) in order to promote an adequate relationship with the patient, to explain the impact of the disease on daily activities and QoL (education, work, household chores, life management);
- information about the opportunity to get in touch with the patient association, if present in the country, should be released as detailed below.

\section{The relationship with the patient association}

In most countries, DebRA is the EB patient association. All national DebRA belong to an umbrella organization known as DebRA International (www.debra-international.org).

- Patients should be informed about the presence of the patient association in their country and the interest to become a member.

- Patient associations contribute to improve patient access to information, reference centres, and social services.

- They also facilitate contact between patients and sharing experience regarding daily life.

- In some countries, they provide financial support and/or fund nurse home care and/or organize vacations for patients and families.

- Finally, they can contribute to promote professional training and research.

\section{Summaries}

The optimization of EB patient healthcare requires the implementation of a wide range of measures. Towards this goal, the establishment in each country of expertise centres, which guarantee a multidisciplinary care, is essential. Equally important is the sharing of standards of care among expertise centres. The present recommendations should easy this process, support clinicians involved in EB care and, overall, contribute to improved patient care and QoL. Nevertheless, multicentre trials are needed, in particular to standardize interventions in wound care, itch and pain management, treatment of pseudosyndactyly and prevention and therapy of 
squamous cell carcinoma [38]. Finally, recent progress in the development of different gene, protein and cell therapy approaches open new perspectives for the treatment of these patients. In addition to the pilot study published by Mavilio and coworkers showing the feasibility of exvivo gene therapy in generalized non-Herlitz JEB [111], the results of clinical trials based on the use of (i) allogenic fibroblasts for local RDEB wound care [112,113] and (ii) allogenic hematopoietic stem cell/mesenchymal cell transplantation for severe RDEB forms [114] have been recently described. In particular hematopoietic stem cells transplantation has been reported to result in significant disease improvement, but not cure, in the majority of treated patients and further studies are ongoing to minimize the severe risks associated with transplantation procedure and to optimize the treatment protocol [114]. These results indicate that effective and specific EB treatments able to block disease progression are likely to become available in the medium term.

\section{Consent}

Written informed consent was obtained from the participants for publication of this review and accompanying images, with additional parental written consent from those under 18 years of age.

\section{Abbreviations}

EB: Epidermolysis bullosa; EBS: Epidermolysis bullosa simplex; DEB: Dystrophic epidermolysis bullosa; GTF: Gastrostomy feeding; JEB: Junctional epidermolysis bullosa; KS: Kindler syndrome; QoL: Quality of life;

RDEB: Recessive DEB; SMARs: Silicone medical adhesive removers.

\section{Competing interests}

MEH has received travel support from Mölnlycke and Pierre Fabre. GT has received travel support from Pierre Fabre. GZ, EBL, AC, CBu, SHR, AD, CFG, AHM, RDLL, MDV, GS, CDR, SLM, CBo have no competing interests.

\section{Authors' contributions}

MEH, GZ, CBo decided the topics to be developed and the methods to be employed, wrote the first recommendation draft and supervised the entire process of recommendation elaboration. $E B$ and $A C$ equally contributed to recommendation preparation: EB performed the literature review and contributed to «care of the EB newborn and infant», «EB care from childhood to adult», «management for surgical procedures», «pain management», «nutritional aspects»; AC performed the literature review and contributed to the «wound care», «skin care», «itch management», "continuity of care», and «management of intercurrent or associated diseases» topics. CBu contributed to «management for surgical procedures», «pain management» topics; SHR contributed to the «care of disease burden» topics, and revised the entire text; AD performed the literature review and contributed to the «wound care», «skin care» topics; GT contributed to «diagnosis of squamous cell carcinoma» and "therapeutic education» topics; CDR contributed to the «care of disease burden» topic; GS contributed to the part on care of newborn and infant; CFG contributed to the «skin care» and «wound care» topics; AHM and RDLL revised the entire text, and contributed to the «occupational therapy» topic and wrote the conclusions; MDV revised the entire text; SLM contributed to the literature review and revised the entire text. All authors have seen and approved the final manuscript.

\section{Acknowledgements}

We wish to thank the following experts who performed recommendation evaluation: Corrado Angelo (Rome), Emmanuelle Bourrat (Paris), Sarah
Chaumon (Paris), Christine Chiaverini (Nice), Isabelle Corset (Paris), Elodie Deladrière (Paris), Biagio Didona (Rome),Vlasta Dragoš (Slovenia), Hélène Dufresne (Paris), Loredana Giraldi (Rome), Jean-Philippe Lacour (Nice), Cécile Lambe (Paris), Ermenegilda Latella (Rome), Juliette Mazereeuw-Hautier (Toulouse), Angela Ranati (Rome), Alberto Eugenio Tozzi (Rome). All French experts are from the French network for rare dermatological diseases (FIMARAD).

We also wish to thank DebRA Italy (www.debraitaliaonlus.org), DeBRA France (www.debra.fr), DEBRA Spain (www.debra.es), DEBRA Portugal (www.debra. pt), DEBRA Slovenia (info@debra-slovenia.si, www.debra-slovenia.si) for the continuous support in patient care organization. Finally, we are grateful to Alberto Eugenio Tozzi for literature search and Lavinia Serra for secretarial assistance.

This work was supported by grants from the Italian Ministry of Health (Ricerca Corrente Program) to MEH and GZ, and from European Commission, DG SANCO (Together against Genodermatoses project, TAG 2007 335).

\section{Author details}

'Dermatology Unit, Bambino Gesù Children's Hospital, IRCCS, Piazza S. Onofrio, 4, 00165 Rome, Italy. 'Laboratory of Molecular and Cell Biology, Istituto Dermopatico dell'Immacolata, IDI-IRCCS, Rome, Italy. ${ }^{3}$ Department of Dermatology, Necker-Enfants Malades Hospital, National reference centre for Genodermatoses (MAGEC), 149 rue de Sèvres, 75015 Paris, France. ${ }^{4}$ Université Paris Descartes - Sorbonne Paris Cité, Institut Imagine, Paris, France.

${ }^{5}$ Dermatology University Clinic, Hospital de Santa Maria, Centro Hospitalar Lisboa Norte EPE, Lisbon, Portugal. 'Department of Dermatology, Hospital Infantil del Niño Jesús, Madrid, Spain. ${ }^{7}$ Department of Dermatology, Hospital Infantil La Paz, Madrid, Spain. ${ }^{8}$ Department of Dermatovenereology, University Medical Centre Ljubljana, Ljubljana, Slovenia. ${ }^{9}$ Section of Dermatology, Fondazione IRCCS Cà Granda-Ospedale Maggiore Policlinico di Milano, Milan, Italy. ${ }^{10}$ Neonatal Intensive Care Unit, Department of Medical and Surgical Neonatology, Bambino Gesù Children's Hospital, IRCCS, Rome, Italy. ${ }^{11}$ Clinical Psychology Unit, Bambino Gesù Children's Hospital, IRCCS, Rome, Italy.

Received: 25 November 2013 Accepted: 16 April 2014

Published: 20 May 2014

\section{References}

1. Fine JD, Bruckner-Tuderman L, Eady RA, Bauer EA, Bauer JW, Has C, Heagerty A, Hintner H, Hovnanian A, Jonkman MF, Leigh I, Marinkovich MP, Martinez AE, McGrath JA, Mellerio JE, Moss C, Murrell DF, Shimizu H, Uitto J, Woodley D, Zambruno G: Inherited epidermolysis bullosa: Updated recommendations on diagnosis and classification. J Am Acad Dermatol 2014, in press. doi:10.1016/j.jaad.2014.01.903.

2. Fine JD: Inherited epidermolysis bullosa. Orphanet J Rare Dis 2010, 5:12

3. Devries DT, Johnson LB, Weiner M, Fine JD: Relative extent of skin involvement in inherited epidermolysis bullosa (EB): composite regional anatomic diagrams based on the findings of the National EB Registry, 1986 to 2002. J Am Acad Dermatol 2004, 50:572-581.

4. Fine JD, Mellerio JE: Extracutaneous manifestations and complications of inherited epidermolysis bullosa: part I. Epithelial associated tissues. J Am Acad Dermatol 2009, 61:367-384.

5. Fine JD, Mellerio JE: Extracutaneous manifestations and complications of inherited epidermolysis bullosa: part II. Other organs. J Am Acad Dermatol 2009, 61:387-402.

6. Hünefeld C, Mezger M, Kern JS, Nyström A, Bruckner-Tuderman L, Handgretinger R, Röcken M: One goal, different strategies-molecular and cellular approaches for the treatment of inherited skin fragility disorders. Exp Dermatol 2013, 22:162-167

7. Garcia-Doval I, Davila-Seijo P, Langan SM: Updated systematic review of randomized controlled trials of treatments for inherited forms of epidermolysis bullosa. Clin Exp Dermatol 2013, 38:92-94.

8. Pope E, Lara-Corrales I, Mellerio J, Martinez A, Schultz G, Burrell R, Goodman L, Coutts P, Wagner J, Allen U, Sibbald G: A consensus approach to wound care in epidermolysis bullosa. J Am Acad Dermatol 2012, 67:904-917.

9. Krämer SM, Serrano MC, Zillmann G, Gálvez P, Araya I, Yanine N, CarrascoLabra A, Oliva P, Brignardello-Petersen R, Villanueva J: DEBRA International. Oral health care for patients with epidermolysis bullosa-best clinical practice guidelines. Int J Paediatr Dent 2012, 22:1-35. 
10. Denyer J, Pillay E: Best practice guidelines for skin and wound care in epidermolysis bullosa. [http://www.debra-international.org/medprofessionals/best-clinical-practice-guidelines-bcpg/]

11. Lanschuetzer CM, Laimer M, Nischler E, Hintner H: Epidermolysis bullosa nevi. Dermatol Clin 2010, 28:179-183.

12. Yuen WY, Jonkman MF: Risk of squamous cell carcinoma in junctional epidermolysis bullosa, non-Herlitz type: report of 7 cases and a review of the literature. J Am Acad Dermatol 2011, 65:780-789.

13. Has C, Castiglia D, del Rio M, Diez MG, Piccinni E, Kiritsi D, Kohlhase J, Itin P, Martin L, Fischer J, Zambruno G, Bruckner-Tuderman L: Kindler syndrome: extension of FERMT1 mutational spectrum and natural history. Hum Mutat 2011, 32:1204-1212.

14. Charlesworth A, Chiaverini C, Chevrant-Breton J, DelRio M, Diociaiuti A, Dupuis RP, El Hachem M, Le Fiblec B, Sankari-Ho AM, Valhquist A, Wierzbicka E, Lacour JP, Meneguzzi G: Epidermolysis bullosa simplex with PLEC mutations: new phenotypes and new mutations. Br J Dermatol 2013, 168:808-814.

15. Schumann $H$, Kiritsi D, Pigors $M$, Hausser I, Kohlhase J, Peters J, Ott H, HylaKlekot L, Gacka E, Sieron AL, Valari M, Bruckner-Tuderman L, Has C: Phenotypic spectrum of epidermolysis bullosa associated with a6 $\beta 4$ integrin mutations. Br J Dermatol 2013, 169:115-124.

16. van den Akker PC, Mellerio JE, Martinez AE, Liu L, Meijer R, Dopping Hepenstal PJ, van Essen AJ, Scheffer H, Hofstra RM, McGrath JA, Jonkman MF: The inversa type of recessive dystrophic epidermolysis bullosa is caused by specific arginine and glycine substitutions in type VII collagen. J Med Genet 2011, 48:160-167.

17. Freeman EB, Köglmeier J, Martinez AE, Mellerio JE, Haynes L, Sebire NJ Lindley KJ, Shah N: Gastrointestinal complications of epidermolysis bullosa in children. Br J Dermatol 2008, 158:1308-1314.

18. Lara-Corrales I, Mellerio JE, Martinez AE, Green A, Lucky AW, Azizkhan RG, Murrell DF, Agero AL, Kantor PF, Pope E: Dilated cardiomyopathy in epidermolysis bullosa: a retrospective, multicenter study. Pediatr Dermatol 2010, 27:238-243.

19. EUCERD Recommendations on Quality Criteria for Centres of Expertise for Rare Diseases in Member States (24 October 2011). [http://www eucerd.eu/]

20. Foster $L$, Holmes $Y$ : Transition from paediatric to adult service in epidermolysis bullosa. Br J Nurs 2007, 16:244-246.

21. Bodemer C, MAGEC-Necker Team: Epidermolysis bullosa in France: management in the National Reference Center for Genodermatosis. Dermatol Clin 2010, 28:401-403. xiv.

22. Duipmans JC, Jonkman MF: Interdisciplinary management of epidermolysis bullosa in the public setting: the Netherlands as a model of care. Dermatol Clin 2010, 28:383-386. xii.

23. Castiglia D, Zambruno G: Epidermolysis bullosa care in Italy. Dermatol Clin 2010, 28:407-409. xiv-xv.

24. Pohla-Gubo G, Hintner $\mathrm{H}$ : Epidermolysis bullosa care in Austria and the Epidermolysis Bullosa House Austria. Dermatol Clin 2010, 28:415-420. xv.

25. Mellerio JE: Epidermolysis bullosa care in the United Kingdom. Dermatol Clin 2010, 28:395-396. xiv.

26. Arbuckle HA: Epidermolysis bullosa care in the United States. Dermatol Clin 2010, 28:387-389. xii.

27. Watson R: Care of epidermolysis bullosa in Ireland. Dermatol Clin 2010, 28:397-399. xiv.

28. Bruckner-Tuderman L: Epidermolysis bullosa care in Germany. Dermatol Clin 2010, 28:405-406. xiv.

29. Murrell DF: Epidermolysis bullosa in Australia and New Zealand. Dermatol Clin 2010, 28:433-438. xvi.

30. Pope E: Epidermolysis bullosa care in Canada. Dermatol Clin 2010, 28:391-392. xiii.

31. Denyer J: Management of severe blistering disorders. Semin Neonatol 2000, 5:321-324.

32. Bello YM, Falabella AF, Schachner LA: Management of epidermolysis bullosa in infants and children. Clin Dermatol 2003, 21:278-282.

33. Goldschneider K, Lucky AW, Mellerio JE, Palisson F, del Carmen Viñuela Miranda M, Azizkhan RG: Perioperative care of patients with epidermolysis bullosa: proceedings of the 5 th international symposium on epidermolysis bullosa, Santiago Chile, December 4-6, 2008. Paediatr Anaesth 2010, 20:797-804.

34. Denyer J: Reducing pain during the removal of adhesive and adherent products. Br J Nurs 2011, 20:S28. S30-S35.

35. Stephen-Haynes J: Skin integrity and silicone: Appeel 'no-sting' medical adhesive remover. Br J Nurs 2008, 17:792-795.
36. Fine JD, Johnson LB, Weiner M, Suchindran C: Assessment of mobility, activities and pain in different subtypes of epidermolysis bullosa. Clin Exp Dermatol 2004, 29:122-127.

37. Van Scheppingen C, Lettinga AT, Duipmans JC, Maathuis CG, Jonkman MF: Main problems experienced by children with epidermolysis bullosa: a qualitative study with semi-structured interviews. Acta Derm Venereol 2008, 88:143-150.

38. Davila-Seijo P, Hernández-Martín A, Morcillo-Makow E, de Lucas R, Domínguez E, Romero N, Monrós E, Feito M, Carretero L, Aranegui B, García-Doval I: Prioritization of therapy uncertainties in dystrophic epidermolysis bullosa: where should research direct to? an example of priority setting partnership in very rare disorders. Orphanet J Rare Dis 2013, 8:61

39. Mellerio JE, Weiner M, Denyer JE, Pillay El, Lucky AW, Bruckner A, Palisson F: Medical management of epidermolysis bullosa: Proceedings of the IInd International Symposium on Epidermolysis Bullosa, Santiago, Chile, 2005. Int J Dermatol 2007, 46:795-800.

40. Khan MT: Podiatric management in epidermolysis bullosa. Dermatol Clin 2010, 28:325-333. x-xi.

41. Mellerio JE: Infection and colonization in epidermolysis bullosa. Dermatol Clin 2010, 28:267-269. ix

42. Lara-Corrales I, Arbuckle A, Zarinehbaf S, Pope E: Principles of wound care in patients with epidermolysis bullosa. Pediatr Dermatol 2010, 27:229-237.

43. Benson RA, Palin R, Holt PJ, Loftus IM: Diagnosis and management of hyperhidrosis. BMJ 2013, 347:66800.

44. Swartling C, Karlqvist M, Hymnelius K, Weis J, Vahlquist A: Botulinum toxin in the treatment of sweat-worsened foot problems in patients with epidermolysis bullosa simplex and pachyonychia congenita. $\mathrm{Br} J$ Dermatol 2010, 163:1072-1076.

45. Figueira EC, Murrell DF, Coroneo MT: Ophthalmic involvement in inherited epidermolysis bullosa. Dermatol Clin 2010, 28:143-152.

46. Pope E, Lara-Corrales I, Mellerio JE, Martinez AE, Sibbald C, Sibbald RG: Epidermolysis bullosa and chronic wounds: a model for wound bed preparation of fragile skin. Adv Skin Wound Care 2013, 26:177-188.

47. Denyer JE: Wound management for children with epidermolysis bullosa. Dermatol Clin 2010, 28:257-264. viii-ix.

48. Chaby G, Senet P, Vaneau M, Martel P, Guillaume JC, Meaume S, Téot L, Debure C, Dompmartin A, Bachelet H, Carsin H, Matz V, Richard JL, Rochet JM, Sales-Aussias N, Zagnoli A, Denis C, Guillot B, Chosidow O: Dressings for acute and chronic wounds: a systematic review. Arch Dermatol 2007, 143:1297-1304.

49. O'Meara S, Al-Kurdi D, Ologun Y, Ovington LG: Antibiotics and antiseptics for venous leg ulcers. Cochrane Database Syst Rev 2010, 20, CD003557.

50. Koning S, van der Sande R, Verhagen AP, van Suijlekom-Smit LW, Morris AD, Butler CC, Berger M, van der Wouden JC: Interventions for impetigo. Cochrane Database Syst Rev 2012, 18, CD003261.

51. Powers JG, Morton LM, Phillips TJ: Dressings for chronic wounds. Dermatol Ther 2013, 26:197-206.

52. AI-Waili NS, Salom K, Butler G, Al Ghamdi AA: Honey and microbial infections: a review supporting the use of honey for microbial control. J Med Food 2011, 14:1079-1096.

53. Jull $A B$, Walker N, Deshpande S: Honey as a topical treatment for wounds. Cochrane Database Syst Rev 2013, 28, CD005083.

54. Flohr C, Heague J, Leach I, English J: Topical silver sulfadiazine-induced systemic argyria in a patient with severe generalized dystrophic epidermolysis bullosa. Br J Dermatol 2008, 159:740-741.

55. Schwieger-Briel A, Kiritsi D, Schumann H, Meiss F, Technau K, BrucknerTuderman L: Grey spots in a patient with dystrophic epidermolysis bullosa. Br J Dermatol 2010, 163:1124-1126.

56. Drucker CR: Update on topical antibiotics in dermatology. Dermatol Ther 2012, 25:6-11

57. Drera B, Castiglia D, Zoppi N, Gardella R, Tadini G, Floriddia G, De Luca N Pedicelli C, Barlati S, Zambruno G, Colombi M: Dystrophic epidermolysis bullosa pruriginosa in Italy: clinical and molecular characterization. Clin Gene 2006, 70:339-347.

58. Almaani N, Liu L, Harrison N, Tanaka A, Lai-Cheong J, Mellerio JE, McGrath JA: New glycine substitution mutations in type VII collagen underlying epidermolysis bullosa pruriginosa but the phenotype is not explained by a common polymorphism in the matrix metalloproteinase- 1 gene promoter. Acta Derm Venereo/ 2009, 89:6-11.

59. Weisshaar E, Szepietowski JC, Darsow U, Misery L, Wallengren J, Mettang T, Gieler U, Lotti T, Lambert J, Maisel P, Streit M, Greaves MW, Carmichael AJ, Tschachler E, Ring J, Ständer S: European guideline on chronic pruritus. Acta Derm Venereol 2012, 92:563-581. 
60. Yosipovitch G, Bernhard JD: Clinical practice. Chronic pruritus N Engl J Med 2013, 368:1625-1634.

61. Calikoglu E, Anadolu R: Management of generalized pruritus in dominant dystrophic epidermolysis bullosa using low-dose oral cyclosporin. Acta Derm Venereol 2002, 82:380-382.

62. Tey HL, Lee AD, Almaani N, McGrath JA, Mills KC, Yosipovitch G: Epidermolysis bullosa pruriginosa masquerading as psychogenic pruritus. Arch Dermatol 2011, 147:956-960.

63. Ozanic Bulic S, Fassihi H, Mellerio JE, McGrath JA, Atherton DJ: Thalidomide in the management of epidermolysis bullosa pruriginosa. $\mathrm{Br} J$ Dermatol 2005, 152:1332-1334.

64. Banky JP, Sheridan AT, Storer EL, Marshman G: Successful treatment of epidermolysis bullosa pruriginosa with topical tacrolimus. Arch Dermatol 2004, 140:794-796.

65. Fine JD: Malignant melanoma and epidermolysis bullosa simplex. JAMA Dermatol 2013, 149:1148-1149.

66. Mavili E, Amaral J, Healey A, Karsli C, Pope E, Connolly B: Percutaneous interventional radiology procedures in patients with epidermolysis bullosa: modifications and challenges. AJR Am J Roentgenol 2010, 195:468-475.

67. Fröhlich S, O'Sullivan E: Airway management in adult patients with epidermolysis bullosa dystrophica: a case series. Anaesthesia 2011, 66:842-843.

68. Herod J, Denyer J, Goldman A, Howard R: Epidermolysis bullosa in children: pathophysiology, anaesthesia and pain management. Paediatr Anaesth 2002, 12:388-397.

69. Ames WA, Levine MF: Response to review by Herod et al. Paediatr Anaesth 2003, 13:370-371. author reply 371.

70. Denyer J: Managing pain in children with epidermolysis bullosa. Nurs Times 2012, 108:21-23.

71. Lin YC, Golianu B: Anesthesia and pain management for pediatric patients with dystrophic epidermolysis bullosa. J Clin Anesth 2006, 18:268-271.

72. Goldschneider KR, Lucky AW: Pain management in epidermolysis bullosa. Dermatol Clin 2010, 28:273-282. ix.

73. Allegaert K, Naulaers G: Gabapentin as part of multimodal analgesia in a newborn with epidermolysis bullosa. Paediatr Anaesth 2010, 20:972-973.

74. Nandi R, Howard R: Anesthesia and epidermolysis bullosa. Dermatol Clin 2010, 28:319-324. $x$.

75. Saroyan JM, Tresgallo ME, Farkouh C, Morel KD, Schechter WS: The use of oral ketamine for analgesia with dressing change in an infant with epidermolysis bullosa: report of a case. Pediatr Dermatol 2009, 26:764-766.

76. Wu J: Deep sedation with intravenous infusion of combined propofol and ketamine during dressing changes and whirlpool bath in patients with severe epidermolysis bullosa. Paediatr Anaesth 2007, 17:592-596.

77. Spiliopoulos S, Sabharwal T, Krokidis M, Gkoutzios P, Mellerio J, Dourado R, Adam A: Fluoroscopically guided dilation of esophageal strictures in patients with dystrophic epidermolysis bullosa: long-term results. AJR Am J Roentgenol 2012, 199:208-212.

78. De Angelis P, Caldaro T, Torroni F, Romeo E, Foschia F, di Abriola GF, Rea F, El Hachem M, Genovese E, D'Alessandro S, Dall'Oglio L: Esophageal stenosis in epidermolysis bullosum: a challenge for the endoscopist. J Pediatr Surg 2011, 46:842-847.

79. Azizkhan RG, Stehr W, Cohen AP, Wittkugel E, Farrell MK, Lucky AW, Hammelman BD, Johnson ND, Racadio JM: Esophageal strictures in children with recessive dystrophic epidermolysis bullosa: an 11-year experience with fluoroscopically guided balloon dilatation. J Pediatr Surg 2006, 41:55-60.

80. Gruskay DM: Nutritional management in the child with epidermolysis bullosa. Arch Dermatol 1988, 124:760-761.

81. Haynes L: Nutrition for children with epidermolysis bullosa. Dermatol Clin 2010, 28:289-301.

82. Hubbard L, Haynes L, Sklar M, Martinez AE, Mellerio JE: The challenges of meeting nutritional requirements in children and adults with epidermolysis bullosa: proceedings of a multidisciplinary team study day. Clin Exp Dermatol 2011, 36:579-583.

83. Ingen-Housz-Oro S, Blanchet-Bardon C, Vrillat M, Dubertret L: Vitamin and trace metal levels in recessive dystrophic epidermolysis bullosa. J Eur Acad Dermatol Venerol 2004, 18:649-653.

84. Lechner-Gruskay D, Honig PJ, Pereira G, McKinney S: Nutritional and metabolic profile of children with epidermolysis bullosa. Pediatr Dermatol 1988, 5:22-27.

85. Kuo DJ, Bruckner AL, Jeng MR: Darbepoetin alfa and ferric gluconate ameliorate the anemia associated with recessive dystrophic epidermolysis bullosa. Pediatr Dermatol 2006, 23:580-585.
86. Fine JD, Johnson LB, Weiner M, Suchindran C: Gastrointestinal complications of inherited epidermolysis bullosa: cumulative experience of the National Epidermolysis Bullosa Registry. J Pediatr Gastroenterol Nutr 2008, 46:147-158.

87. Fine JD, Tamura T, Johnson L: Blood vitamin and trace metal levels in epidermolysis bullosa. Arch Dermatol 1989, 125:374-379.

88. Sidwell RU, Yates $\mathrm{R}$, Atherton D: Dilated cardiomyopathy in dystrophic epidermolysis bullosa. Arch Dis Child 2000, 83:59-63.

89. Haynes L, Atherton DJ, Ade-Ajayi N, Wheeler R, Kiely EM: Gastrostomy and growth in dystrophic epidermolysis bullosa. Br J Dermatol 1996, 134:872-879.

90. Stehr W, Farrell MK, Lucky AW, Johnson ND, Racadio JM, Azizkhan RG: Non endoscopic percutaneous gastrostomy placement in children with recessive dystrophic epidermolysis bullosa. Pediatr Surg 2008, 24:349-354.

91. Colomb V, Bourdon-Lannoy E, Lambe C, Sauvat F, Hadj Rabia S, Teillac D, De Prost $Y$, Bodemer $C$ : Nutritional outcome in children with severe generalized recessive dystrophic epidermolysis bullosa: a short- and long-term evaluation of gastrostomy and enteral feeding. $\mathrm{Br} J$ Dermatol 2012, 166:354-361.

92. Yuen WY, Duipmans JC, Molenbuur B, Herpertz I, Mandema JM, Jonkman MF: Long-term follow-up of patients with Herlitz-type junctional epidermolysis bullosa. Br J Dermatol 2012, 167:374-382.

93. Burger-Rafael M: Physical medicine and epidermolysis bullosa. In Life with epidermolysis bullosa, etiology, diagnosis, multidisciplinary care and therapy. 1st edition. Edited by Fine JD, Hintner H. Wien: Springer; 2009:278-286.

94. Prinz F, Weiss H: Occupational therapy in epidermolysis bullosa. A holistic concept for intervention from infancy to adult. Wien: Springer; 2012

95. Venugopal SS, Murrell DF: Treatment of skin cancers in epidermolysis bullosa. Dermatol Clin 2010, 28:283-287. ix-x.

96. Torrelo A, Zambrano A: Crusted scabies in a girl with epidermolysis bullosa simplex. Br J Dermatol 2000, 142:197-198.

97. Angelo C, Pedicelli C, Provini A, Annessi G, Zambruno G, Paradisi M: Successful treatment of Norwegian scabies with ivermectin in a patient with recessive dystrophic epidermolysis bullosa. Minerva Pediatr 2004, 56:353-357.

98. Kim J, Loh CH, Murrell DF: Epidermolysis bullosa pruriginosa triggered by scabies infestation. J Dermatol 2013, 40:562-563.

99. Sibaud V, Roul S, Leaute-Labreze C, Meneguzzi G, Taïeb A: Atopic dermatitis: therapeutic challenge in an infant with dystrophic epidermolysis bullosa. Br J Dermatol 2002, 147:350-352.

100. Therapeutic patient education: definition, goal and organisation. [http:// www.has-sante.fr/portail/upload/docs/application/pdf/2008-12/ therapeutic_patient_education_tpe_-_definition_goals_and_organisation__quick_reference_guide.pdf]

101. Fine JD, Johnson LB, Weiner M, Suchindran C: Impact of inherited epidermolysis bullosa on parental interpersonal relationships, marital status and family size. Br J Dermatol 2005, 152:1009-1014.

102. Yuen WY, Duipmans JC, Jonkman MF: The needs of parents with children suffering from lethal epidermolysis bullosa. Br J Dermatol 2012, 167:613-618.

103. Tabolli S, Pagliarello C, Uras C, Di Pietro C, Zambruno G, Castiglia D, Sampogna F, Abeni D: Family burden in epidermolysis bullosa is high independent of disease type/subtype. Acta Derm Venereol 2010, 90:607-611.

104. Dures E, Morris M, Gleeson K, Rumsey N: The psychosocial impact of epidermolysis bullosa. Qual Health Res 2011, 1:771-782.

105. Adni T, Martin K, Mudge E: The psychosocial impact of chronic wounds on patients with severe epidermolysis bullosa. J Wound Care 2012, 21:528. 530-536, 538.

106. Feldmann R, Weglage J, Frosch M: Cognitive function in patients with epidermolysis bullosa: social adjustment and emotional problems. Klin Padiatr 2012, 224:22-25.

107. Margari F, Lecce PA, Santamato W, Ventura P, Sportelli N, Annicchiarico G, Bonifazi E: Psychiatric symptoms and quality of life in patients affected by epidermolysis bullosa. J Clin Psychol Med Settings 2010, 17:333-339.

108. Tabolli S, Sampogna F, Di Pietro C, Paradisi A, Uras C, Zotti P, Castiglia D, Zambruno G, Abeni D: Quality of life in patients with epidermolysis bullosa. Br J Dermatol 2009, 161:869-877.

109. Frew JW, Martin LK, Nijsten T, Murrell DF: Quality of life evaluation in epidermolysis bullosa (EB) through the development of the QOLEB 
questionnaire: an EB-specific quality of life instrument. $\mathrm{Br} J$ Dermatol 2009, 161:1323-1330.

110. Moss K: Contact at the borderline: psychoanalytic psychotherapy with $E B$ patients. Br J Nurs 2008, 17:449-455.

111. Mavilio F, Pellegrini G, Ferrari S, Di Nunzio F, Di lorio E, Recchia A, Maruggi G, Ferrari G, Provasi E, Bonini C, Capurro S, Conti A, Magnoni C, Giannetti A, De Luca M: Correction of junctional epidermolysis bullosa by transplantation of genetically modified epidermal stem cells. Nat Med 2006, 12:1397-1402.

112. Petrof G, Martinez-Queipo M, Mellerio JE, Kemp P, McGrath JA: Fibroblast cell therapy enhances initial healing in recessive dystrophic epidermolysis bullosa wounds: results of a randomised, vehicle-controlled trial. Br J Dermatol 2013, 169:1025-1033.

113. Venugopal SS, Yan W, Frew JW, Cohn HI, Rhodes LM, Tran K, Melbourne W Nelson JA, Sturm M, Fogarty J, Marinkovich MP, Igawa S, Ishida-Yamamoto A, Murrell DF: A phase II randomized vehicle-controlled trial of intradermal allogeneic fibroblasts for recessive dystrophic epidermolysis bullosa. J Am Acad Dermato 2013, 69:898-908. e7.

114. Tolar J, Wagner JE: Allogeneic blood and bone marrow cells for the treatment of severe epidermolysis bullosa: repair of the extracellular matrix. Lancet 2013, 382:1214-1223.

doi:10.1186/1750-1172-9-76

Cite this article as: El Hachem et al: Multicentre consensus

recommendations for skin care in inherited epidermolysis bullosa.

Orphanet Journal of Rare Diseases 2014 9:76.

\section{Submit your next manuscript to BioMed Central} and take full advantage of:

- Convenient online submission

- Thorough peer review

- No space constraints or color figure charges

- Immediate publication on acceptance

- Inclusion in PubMed, CAS, Scopus and Google Scholar

- Research which is freely available for redistribution 